\title{
COMPASIÓN, TEMOR Y CATARSIS. LA LECTURA NIETZSCHEANA DE ARISTÓTELES
}

Pity, fear and catharsis. Nietzsche's interpretation of Aristotle

\author{
Alfredo Abad \\ Universidad Tecnológica de Pereira (Colombia)
}

\begin{abstract}
Resumen: Desde El nacimiento de la tragedia hasta los Fragmentos póstumos del último periodo, Nietzsche alude a la especificación aristotélica de los efectos trágicos y la catarsis con un categórico rechazo. Sin embargo, estos planteamientos no necesariamente se deben identificar como válidos, al menos en lo concerniente al sentido atribuido a las percepciones aristotélicas que están principalmente contenidas en la Poética. El texto ilustra las referencias establecidas por Nietzsche con el fin de esclarecer su manifiesto crítico y plantear algunos interrogantes sobre la legitimidad de sus objeciones, teniendo presente el derrotero preceptivo de Aristóteles en su libro sobre la tragedia.

Palabras clave: Temor - compasión - tragedia - Nietzsche
\end{abstract}

ABSTRACT: From The Birth of Tragedy to the Posthumous Fragments of the last period, Nietzsche refers to the Aristotelian specification of the tragic effects and catharsis with a categorical rejection. However, these approaches do not necessarily need to be identified as valid, at least in the sense attributed by Aristotle in his Poetics. The paper illustrates the benchmarks established by Nietzsche to clarify its manifesto and raise some critical questions about the legitimacy of their objections, bearing in mind the prescriptive itinerary by Aristotle in his book.

Key words: Fear - Pity - Tragedy - Nietzsche

De acuerdo a la definición aristotélica, la tragedia es «... la imitación de una acción esforzada y completa, de cierta amplitud, en lenguaje sazonado, separada cada una de las especies (de aderezos) en las distintas partes, actuando los personajes y no mediante relato, y que mediante compasión y temor lleva a cabo la purgación de tales afecciones» ${ }^{1}$. La conformación de la representación trágica con el objetivo de generar los efectos señalados es el aspecto frente al cual Nietzsche presenta su más enconada oposición. Es bien importante tener presente este manifiesto por cuanto, a partir de él, se intenta poner en evidencia los errores del contenido aristotélico y concebir, por lo demás, la identidad de lo que Nietzsche establece como estrictamente trágico. Es preciso indicar el hecho de que las alusiones por parte del filósofo alemán no se circunscriben solo al ámbito de los efectos trágicos y la catarsis. En El nacimiento de la tragedia hay algunas precisiones correspon-

1. Aristóteles, Poética, 49b 24-28 (ed. trilingüe de V. García Yebra, Madrid: Gredos, 1974). 
dientes a la constitución de la tragedia a partir de la fortaleza escénica del pathos sobre la acción, perspectiva que intenta identificar el ámbito de la música como el dominio sobre el cual el coro primigenio se desenvolvía sin atributos o exigencias escénicas complejas. La simplicidad que se reconoce en las obras de Esquilo, pobres de acción y de efectos dramáticos, tendrían más afinidad con el proceso en el que Nietzsche reconoce el origen del género.

Aristóteles, en cambio, precisa el afianzamiento del drama en tanto describe las exigencias dramáticas que la evolución del género tendría consolidadas en la obra de Sófocles. Pero no se trata solo de una elección estética. El estagirita asume la necesidad de que la obra integre estos refinamientos estilísticos con un fin del todo distinto, pues su pretensión implica el acceso a un contenido patético que surge, a pesar de la consideración nietzscheana, de la acción dramática. La distinción que hay que demarcar en este punto implica el carácter teleológico al cual apunta Aristóteles cuando otorga una alta estimación a la tragedia que logre desplegar dicho pathos, a partir de un refinamiento dramático. Se trata en este caso de acceder a un contenido ético y político que brinda la tragedia y por el cual Nietzsche no dejará de revelar su antipatía procurando resaltar un sentido trágico $\mathrm{y}$, por ende, enteramente ateleológico.

A pesar del radicalismo nietzscheano en este punto, es claro que la tragedia griega sí posee un contenido que desborda la mera exaltación del dionisismo, por ende, de acuerdo al alto contenido ético-político que se desplegaba en las representaciones, el enfoque aristotélico solo puede asimilarse como una perversión del manifiesto original de la tragedia en tanto se asuma la percepción trágico-metafísica que Nietzsche intenta consolidar en su pensamiento. Si la compasión y el temor como efectos trágicos son impugnados dentro de este mismo esquematismo, dicho rechazo se debe al dominio a partir del cual se interpreta la tragedia griega, en el que Nietzsche consolida desde la primera de sus obras un ideario trágico ${ }^{2}$.

\section{LA CRÍTICA DE LOS EFECTOS TRÁGICOS}

Dentro del nutrido conjunto de comentarios que la tradición ha hecho a la Poética y en especial al sentido de la catarsis derivada de los efectos trágicos, puede

2. Dentro de la confrontación Nietzsche-Aristóteles se debe tener en cuenta una posible inconmensurabilidad entre ambos enfoques, la cual da origen a muchos equívocos. Es claro que los propósitos de Nietzsche se mueven dentro de un plano que está más allá del asunto propiamente filológico y genético sobre la tragedia griega, razón por la cual puede estimarse que las interpretaciones nietzscheanas no deben ser acogidas como argumentaciones que en efecto transgredan el contenido de la Poética. Sin embargo, si bien se tiene claro que el propósito de Nietzsche es estimar una perspectiva sobre lo trágico más que la tragedia misma en tanto género dramático, sí existen puntos en los que las aseveraciones de Nietzsche pueden ser contrastadas, pues se sustentan en una interpretación de la Grecia antigua y de su acontecer alrededor del fenómeno de la tragedia. En la tercera de sus Intempestivas, Nietzsche establece como criterio para abordar el pasado, no un acercamiento docto y poco fértil en torno a un acontecimiento histórico, sino un ámbito creativo que se haga presente y legitime artísticamente el papel del filólogo. A pesar de esto, y de la validez de dicha empresa, es necesario indicar que dentro de este recorrido Nietzsche deja inscritas ciertas apreciaciones que simplemente no pueden ser acogidas sin más, razón por la cual es necesario hacer una revisión de su perspectiva sobre Aristóteles. 
asumirse que la compasión y el temor aparecen como derivaciones certeras de una obra trágica con una finalidad que en algunos casos puede identificarse bajo aspectos morales o políticos. Si bien esta es una asimilación bastante esquemática de la representación aristotélica, es suficiente para enfocar el sentido de la animadversión que Nietzsche pone allí. Para que esta sea enfocada de manera más propicia, vale la pena identificar algunos de los aspectos sobre los cuales Aristóteles dirige su atención, procurando resaltar sus posibilidades y contrastarlas con la antipatía que hacia ellas revela Nietzsche. Dentro del contenido teleológico que rige la presentación de la tragedia griega por parte del estagirita, se establece cómo la compasión y el temor deben concebirse como objetivos sobre cuya expresión se identifica el contenido catártico de la obra y, desde esta misma perspectiva, su utilidad. Esta última se orienta hacia la posibilidad de que en el alma del espectador se dé una valoración de índole ética, no en el sentido de un aprendizaje moral, sino de proyección en la que se afiance la interacción obraespectador a partir del desenvolvimiento catártico del alma, entendida como expresión de caracteres, es decir, de su referencialidad hacia diversos ámbitos del ethos. En este sentido, Paul Ricoeur examina las posibilidades de la obra trágica para determinar justamente que la orientación señalada por Aristóteles obedece no tanto a una presentación de una verdad, sino a la mímesis ${ }^{3}$ verosímil de la misma con un objetivo claro. «La poesía no pretende probar absolutamente nada; su finalidad es mimética, y tengamos en cuenta que [...] su objetivo es componer una representación esencial de las acciones humanas; su característica peculiar es decir la verdad por medio de la ficción, de la fábula, del mythos trágico» ${ }^{4}$.

Es ya un lugar común estipular, de acuerdo con Aristóteles, que la mímesis en una tragedia representa no a hombres sino acciones cuyo fin es el de concretar una catarsis. A pesar de la acertada interpretación psicológica y ética que el estagirita realiza, Nietzsche no parece muy afín a la misma y no reconoce en absoluto cómo la estimación señalada sí ofrece ciertas claves de comprensión e inteligibilidad dignas de tenerse en cuenta, no solo como especificación de la tragedia desde una perspectiva estética y preceptiva, sino también desde una apreciación que identifica un pensamiento trágico contenido en la Poética a partir de la concepción allí establecida de la hamartía o yerro trágico ${ }^{5}$. Pero, por supuesto, Nietzsche confronta la percepción aristotélica desde una óptica completamente distinta, y por ello, a la

3. El término mímesis debe asumirse como representación o figuración creativa más que el acostumbrado y a veces desorientador sentido que lo asimila como imitación.

4. P. Ricoeur, La metáfora viva, Madrid: Trotta, 2001, p. 20.

5. Por cuanto la profundización del concepto derivaría en un examen más detallado sobre el mismo, se considera suficiente indicar cómo a través de él Aristóteles concibe la imposibilidad de esclarecer los signos que determinan el sino del personaje sobre el cual recae la identificación del yerro. En otras palabras, el estagirita sí abre un espacio en el que se puede estimar que dicho error no obedece a una culpabilidad de quien ejecuta una acción sino a una presencia inexorable de ciertas circunstancias por las cuales se identifica como una equivocación o un fracaso y no un pecado o falta moral. De esta manera, esta concepción del yerro se puede interpretar como trágica dentro de la exposición de la Poética. De hecho, el personaje no "cae en la desdicha por su bajeza o maldad, sino por algún yerro» (Poética, 53 a 9-10), de donde se colige la apertura hacia una caracterización irracional o trágica que se cruza en la acción, tal como acontece en Edipo, paradigma de quien, más que ejecutar un error, cae en él. De hecho, a partir del propio Nietzsche, en la aceptación de lo trágico se evidencia la comprensión de los aspectos terribles de la existencia, es decir, aquellos espacios cuya inteligibilidad es proscrita. 
hora de determinar la característica que él ve plasmada en la tragedia griega como esencial dentro de un auténtico arte afirmativo y vital, enfatiza el carácter tónico que de allí se desprende, evitando apreciarla a través de los dos efectos trágicos especificados por Aristóteles. Y está claro que invocando las particularidades de un arte que dé un sí absoluto a la existencia, los planteamientos extraídos de los efectos trágicos contrastan con la fuerza y necesidad del gran estilo que estarían consignados en el arte trágico griego marginado de cualquier proyección moral.

Nietzsche intenta afianzar la sabiduría dionisiaca contrastándola con los esquemas morales que él ve plasmados en la visión aristotélica de la tragedia. Asume, pues, como propio de esta el carácter individual exaltado en el proceso de identificación de los héroes, noción que por supuesto le hace justicia, dado que la acción trágica definida por el filósofo antiguo siempre está situada en un contexto determinado. Al respecto, Nietzsche se sentirá obligado a rechazar tajantemente esta orientación, pues contradice los supuestos schopenhauerianos en los que se sustenta su apreciación. Es por ello por lo que, aludiendo directamente a Aristóteles, afirma: «A pesar del miedo y la compasión, somos los hombres que viven felices, no como individuos, sino como lo único viviente, con cuyo placer procreador estamos fundidos» ${ }^{6}$. De acuerdo a la identificación que configura la cita, es en la aceptación colectiva o universal en donde se detalla el placer trágico de la voluntad del mundo, y no en la apreciación y acción individual tan cara a los supuestos del estagirita.

Esta asimilación educativa y moral plasmada en el horizonte aristotélico contradice la percepción del arte trágico como estimulante vital, con lo cual los efectos trágicos son señalados como asimilaciones empobrecidas de la fuerza o de lo que más adelante reconoce Nietzsche como gran estilo en concordancia con una estética fisiológica, presentes en el arte trágico.

En repetidas ocasiones yo he puesto el dedo sobre el gran malentendido de Aristóteles, cuando creyó reconocer en dos efectos deprimentes, el temor y la compasión, los afectos trágicos. Si él tuviera razón, la tragedia sería un arte mortalmente peligroso: nos tendríamos que prevenir contra ella [...] El arte, que además es el gran estimulante de la vida, una ebriedad en el vivir, una voluntad de vivir, se convertiría aquí, puesto al servicio de un movimiento descendente, reducido, por así decirlo, a una especie de criadero del pesimismo, en nocivo para la salud?

Aquí se revela no solo una confrontación para con la postura aristotélica sino una interpretación de la misma que contradice uno de los supuestos fundamentales del abordaje de la tragedia griega: su carácter educativo y moral. Por supuesto, Nietzsche parte de su propia estipulación, pues en él se configura toda la visión trágica que estima los efectos morales como derivaciones espurias de un arte pleno de embriaguez y fuerza dionisíaca. La censura de Nietzsche se centra en el hecho de que la compasión y el temor son efectos negativos que no proporcionan más que debilidad. En ese sentido se comprende cómo el anterior fragmento se si-

En este caso, el concepto de hamartía tiene, pues, las características plenas para reconocer en él un ejemplo de la especificidad trágica que Aristóteles subraya en su obra.

6. F. Nietzsche, El nacimiento de la tragedia, trad. de A. Sánchez Pascual, Madrid: Alianza, 1997, pp. 138-139.

7. FP IV, 15 [10]. 
túe bajo el título «Qué es trágico», pues corrobora la lectura de la tragedia a través de la óptica en la que la crudeza y radicalidad de los aspectos más oscuros de la existencia no solo son aceptados, sino ansiados a través de un arte afirmativo. La tragedia griega, antes que aplacar, excita, por ello en el mismo fragmento se asume: «... solo la absoluta mendacidad de un sistemático puede al final desconocer -: que la tragedia es un tónico» ${ }^{8}$.

Es importante resaltar cómo a pesar de la acendrada crítica contra la percepción aristotélica, la tragedia griega sí muestra un contenido educativo y político que Nietzsche omite al fundar su apreciación desde sus propios supuestos. En la Orestiada de Esquilo existen algunas alusiones al tipo de relación dada entre la concepción educativa y política que concuerda de manera más clara con la perspectiva aristotélica. Al respecto Jaeger menciona: «Aristóteles dice con razón que los personajes de la antigua tragedia no hablan retóricamente, sino políticamente. Todavía en las grandiosas palabras con que terminan las Euménides, con su fervorosa imploración por la prosperidad del pueblo ático y su reafirmación inconmovible de la fe en el orden divino que lo rige, se manifiesta el verdadero carácter político de su tragedia»"

El tono conciliador con el que termina la trilogía citada se encuentra a mucha distancia del vital y altivo espíritu con el que Nietzsche quiere caracterizar la tragedia antigua, como expresión de un carácter aristocrático que puede rastrearse en muchas de sus expresiones, mas no en todas. Debe precisarse, entonces, que su interpretación de la misma es una adaptación por la cual su propia concepción trágica logra constituirse y clarificarse. Por cuanto el objetivo de este texto no es hacer manifiestos los equívocos filológicos de la lectura nietzscheana de la tragedia, es suficiente asumir que su imagen de la misma, al margen de todo presupuesto moral, dista mucho de lo que el contexto de la época de su manifestación logra poner en evidencia ${ }^{10}$.

Por supuesto, es importante tener en cuenta que los límites que Nietzsche coloca frente a las posturas aristotélicas están fundamentados en una apreciación filosófica que desborda los equívocos filológicos frente a la interpretación de la tragedia griega. En este sentido, los esguinces creados por la animadversión frente a la compasión y el temor como efectos que no pueden ser tenidos en cuenta, solo pueden apreciarse a partir de una comprensión del arte trágico desde la óptica en la cual el arte afirmativo que Nietzsche ve plasmado allí es un correlato del devenir trágico que, como physis abisal ${ }^{11}$, se revela en las apreciaciones que el

8. Ibid.

9. W. Jaeger, Paideia: los ideales de la cultura griega, Bogotá: FCE, 1994, pp. 224-225.

10. Las precisiones sobre el valor político de la tragedia como institución plenamente configurada en la Antigüedad dan al traste con las aseveraciones nietzscheanas que niegan su condición. Así, se puede indicar cómo «la tragedia no es solo una forma de arte: es una institución social que la ciudad, por la fundación de los concursos trágicos, sitúa al lado de sus órganos políticos y judiciales» (J.-P. Vernant y P. Vidal, Mito y tragedia en la Grecia antigua I, Madrid: Taurus, 1987, p. 26). Se trata, por lo tanto, de una especificidad que Nietzsche infravalora procurando consolidar su apropiación interpretativa, en la cual los valores que cree encontrar en la cultura griega serían los mismos que definen su ideal trágico. Sería prudente indicar aquí que, efectivamente, la línea interpretativa por donde transita Nietzsche se inscribe en el terreno de la filología romántica y creativa, desde la cual los presupuestos ortodoxos y positivistas de la crítica textual no tenían mucha importancia.

11. Con el término se hace alusión al desenvolvimiento trágico signado a través del carácter creador-destructor de la voluntad de poder. A este propósito K. Löwith ha identificado este flujo 
filósofo alemán plasma desde el primero de sus libros hasta los esbozos maduros consignados en sus últimos fragmentos póstumos. Por esta razón, los espacios de afirmación crítica frente al fenómeno moral se dan en el contexto de una aprehensión de una ontología trágica, en la que los misterios dionisíacos que Nietzsche asume inscritos en el desarrollo de la tragedia griega se manifiestan como una derivación del crear-destruir entronizado en el eterno retorno de la vida. Así, contrario a los efectos morales, la afirmación de la existencia en medio del dolor se ve reflejada en estos misterios:

... vida eterna, el eterno retorno de la vida, el futuro prometido y consagrado en la procreación, el triunfante decir sí a la vida por encima de la muerte y el cambio, la vida verdadera como supervivencia colectiva [...] en la doctrina de los misterios el dolor queda santificado: los «dolores de la parturienta» santifican el dolor en cuanto tal, todo devenir, todo crecer, todo lo que es una garantía del futuro, implica dolor; para que exista el placer de crear, tiene que existir también el tormento de la parturienta... Yo no conozco una simbólica más alta12.

En esta exaltación el dolor se concibe como estímulo, ante lo cual la presentación de los efectos trágicos aristotélicos se aprecia desde la imposibilidad que de ellos deriva para el acceso a una visión auténticamente trágica. La determinación de la compasión y el temor como objetivo de la tragedia es asimilada por Nietzsche como una consideración moral ajena al entusiasmo jovial por el cual se dice sí incluso a lo más problemático. Deleuze precisa la controversia con los efectos trágicos cuando contrapone a ellos el esquema entusiástico del gozo trágico: «Lo trágico es alegría. Pero esto quiere decir que la tragedia es inmediatamente alegre, que no apela al miedo y a la piedad del espectador obtuso, auditor patológico y moralizador que cuenta con ella para asegurar el buen funcionamiento de sus sublimaciones morales o de sus purgaciones médicas» ${ }^{13}$.

¿Qué significa que la tragedia sea alegre? Nietzsche identifica lo trágico como una sobreabundancia de vitalidad cuya propiedad consiste en afirmar la existencia aun con sus aspectos más terribles. Esta perspectiva metafísica concibe lo trágico no solo como una percepción ética sino como asimilación dada desde el carácter abisal que se desprende del devenir. El decirle sí a este carácter corresponde, pues, al manifiesto por el que la tragedia griega debe concebirse inmersa en los atributos por los que Nietzsche resalta el afianzamiento y aceptación de la problematicidad, caso contrario a lo que, según él, ocurre en la asimilación moral de Aristóteles.

La psicología del orgiasmo, entendido como un sentimiento desbordante de vida, dentro del cual el dolor mismo solo actúa como un estimulante, me dio la clave para entender el sentimiento trágico, que ha sido malentendido tanto por Aristóteles como especialmente por parte de los pesimistas. [...] No para desembarazarse del espanto y la compasión, y para purificarse de un afecto peligroso mediante una vehemente descarga de ese mismo afecto - ese fue el camino de Aristóteles: sino

como «una physis engendrante-aniquiladora que todo lo soporta y domina» («Las lecciones sobre Nietzsche de Heidegger», en K. Löwith, Heidegger, pensador de un tiempo indigente. Sobre la posición de la filosofía en el siglo XX, Buenos Aires: FCE, 2006, p. 312).

12. FP IV, 24 [1] 9.

13. G. Deleuze, Nietzsche y la filosofía, Barcelona: Anagrama, 2002, p. 29. 
para, más allá del espanto y la compasión, disfrutar del eterno placer del crear y del devenir... ${ }^{14}$.

La referencia a Aristóteles confirma el antagonismo en tanto sugiere todo aquello que niega la exuberancia trágica y afirmativa de la vida en su proceso eterno de creación y destrucción. En este sentido, Nietzsche unifica las perspectivas práctica y teorética en las que el dominio trágico del devenir esboza su unidad a partir de la exigencia de un proceso en el que la praxis heroica esbozada en la tragedia se adecúe al desenvolvimiento inocente del devenir. Esta disposición, tal como se ha mostrado, proviene de la percepción nietzscheana que margina cualquier identificación moral o política, y, si bien se ha mencionado aquí que la tragedia sí sugiere una perspectiva derivada de tales ámbitos, la precisión de Nietzsche debe asumirse como derivación concatenada a una imagen general de una filosofía trágica.

\section{2 .LA PRESENCIA AMBIGUA DE LA CATARSIS}

Nietzsche concibe la catarsis (purgación) como un elemento en el que el declive de la tragedia encuentra un rasgo predominante, a partir de los efectos morales que cree encontrar en la asimilación aristotélica. La oscuridad del concepto dentro de la Poética ha generado controversias que justamente podrían llegar a justificar la ambigüedad con que Nietzsche lo discute ${ }^{15}$. Antes de hacer intervenir el reproche nietzscheano frente al mismo, es imprescindible especificar el sentido de la indicación original. La dirección más precisa en torno al problema es la que determina la compasión y el temor en tanto efectos trágicos, como generadores de la catarsis. Son ellos los agentes y no los pacientes en relación a la apropiación que realiza el espectador en la medida en que participa activamente en la recepción de la tragedia. Por ello «no se trata de los sentimientos del personaje trágico, sino de los que la tragedia debe producir en el espectador o lector» ${ }^{16}$. No obstante, ¿qué tipo de catarsis, y a dónde apunta, si deriva de los efectos señalados? Una cosa es que la compasión y el temor la generen pero ¿qué es entonces lo que purga, lo que limpia? La respuesta a esta pregunta debe ligarse necesariamente a la relación que Nietzsche cree establecer a partir de allí con la que, según él, es la equivocada percepción del estagirita. A través de esta especificidad se puede detallar de manera más clara la orientación que mueve no solo la crítica de Nietzsche sino el espectro mismo de la tragedia griega en relación a los efectos que generaba.

De la compasión y el temor surge la catarsis, de allí proviene la cura o limpieza de afecciones similares a las que se enuncian literalmente. Esta interpretación no es la única y no ofrece una claridad absoluta, sin embargo, ton toiouton, cuyo significado es de tales, de semejantes y que implica una relación o una natura-

14. FP IV, $24[1] 9$.

15. En 49 b27-28 se encuentra la referencia, única en toda la Poética, a la catarsis. El concepto puede asimilarse a una función terapéutica y curativa. El término se usaba en el ámbito médico-religioso, y aunque no existe una interpretación definitiva sobre el mismo, es adecuado juzgar la catarsis aristotélica en esta dirección, pues su apropiación evidencia el objetivo curativo y, por extensión, políticoeducativo, que en el espectador se manifestaba una vez se consolidaran los efectos trágicos.

16. V. García Yebra, Sobre la interpretación de 49b27-28, en Poética, cit., p. 381. 
leza de índole similar, da a entender que la catarsis se ejerce sobre afecciones (pathématon $)^{17}$ semejantes, de donde se asume que la dirección a donde apunta la purgación no se refiere necesariamente solo a la compasión y al temor ${ }^{18}$, sino a padecimientos parecidos. Por ende, la catarsis se produce en afecciones de naturaleza similar y no en los efectos referidos, como podría interpretarse a través de la asimilación que del problema realiza Nietzsche. En este caso, se ilustra una percepción en la que el filósofo alemán solo concibe la especificidad de la catarsis en relación a lo que él denomina los efectos morales nocivos ya señalados. De esta manera se precisan los pasajes en que se trae a colación la temática, en cuyo dominio se manifiesta siempre la tendencia a establecer un carácter moral en la ilustración aristotélica.

Aristóteles quería que se considerase la tragedia como un purgativo de la compasión y el espanto, - como útil descarga de dos afectos mórbidos desmesuradamente acumulados...

Los otros afectos tienen un efecto tónico: pero solo dos afectos depresivos - y esos son, por tanto, especialmente perjudiciales y malsanos - la compasión y el espanto, deberían, según Aristóteles, eliminarse del ser humano mediante la tragedia como un purgativo: la tragedia, al excitar en exceso esos peligrosos estados, libra de ellos al ser humano - a este lo hace mejor. La tragedia como una cura contra la compasión ${ }^{19}$.

En este fragmento se concreta el sentido que Nietzsche cree ver en las observaciones de la Poética bajo un tono que de todas maneras no deja de presentar cierta superficialidad. ¿̇Puede establecerse sin más que efectivamente Aristóteles haya malentendido el fin de la tragedia? En primer lugar, la tragedia no es un purgativo de la compasión y el temor como lo cree Nietzsche, pues otra cosa es lo que dice la definición de Aristóteles. Por el contrario, la tragedia sí busca la purgación, mas no de los efectos señalados sino a través de ellos. En este caso es preciso resaltar cómo el atributo principal de la indicación crítica nietzscheana se encuentra viciado por un enfoque que no le pertenece a la ya citada definición.

Mientras Nietzsche involucra el contenido moral afianzándose en dos efectos como la compasión y el temor, le imprime a la consideración de Aristóteles un tono negativo que es difícil de asimilar si se involucra el sentido amplísimo a que apunta. Por cuanto la compasión y el temor no están libres de determinarse como aspectos ajenos a una referencialidad mucho más vasta en la que se involucran otras afecciones, la estipulación de una tonalidad en la que el espectador se libera o descarga de las mismas es imprescindible a través del posicionamiento entusiástico del que la reviste. Este punto no es atendido por Nietzsche de la manera en que debería considerarse el que quizá es uno de los aspectos más trascendentales de la tragedia griega, y al cual Aristóteles dedica una atención especial.

La obsesión por asumir una interpretación moral de la catarsis no permite centrar el efecto al que apunta la definición de la Poética desde un aspecto fisiológico, tal como se desprende de su interpretación médica y terapéutica. Los efectos

17. En este caso como en el anterior los términos aparecen en genitivo en el original aristotélico.

18. Pues tal como hemos visto, antes bien, de estas procede la catarsis.

19. FP IV, 15 [10]. 
del arte trágico sobre el espectador no lo llevan de ninguna manera a un empobrecimiento anímico y mucho menos corporal, salvo a partir de la consideración nietzscheana de acuerdo a la cual la catarsis genera un efecto calmante. Si bien la exigencia que Nietzsche estipula para el arte trágico griego intenta contradecir la estimación aristotélica asumiéndola como apocamiento vital, es necesario indicar que la catarsis sí conduce a una exaltación fisiológica que tiene un valor muy importante dentro del análisis que se realiza sobre los efectos a los que debe conducir el arte trágico. Por ello, se debe resaltar cómo los juicios aristotélicos coinciden casi enteramente con las condiciones a que Nietzsche somete el arte, por cuanto el objetivo de la catarsis no es calmar o empobrecer sino conminar a una consecución de un equilibrio corporal. Así parece llevarlo a cabo no solo el texto aludido sino los demás comentarios relacionados con los efectos catárticos de la música y, en general, de toda participación entusiástica. En ese sentido, Laín Entralgo ha expresado cómo el mecanismo de la catarsis «sería de índole psicofisiológica, y hasta puramente fisiológica y somática; la psicología de Aristóteles es siempre psicofisiología, y no se aparta de tal regla la explicación aristotélica de los fenómenos religiosos, en este caso el entusiasmo» ${ }^{20}$. Con lo anterior se puede indicar el hecho de que la tendencia aristotélica se aleja no solo de una mera interpretación moral tal como la plantea Nietzsche, sino del apocamiento fisiológico que el mismo filósofo cree encontrar cuando desvía la presencia de la catarsis hacia la emotividad negativa de los efectos trágicos ${ }^{21}$.

Ahora bien, el efecto purgativo (y, por ende, somático) de la tragedia griega, como característica que hace ver en la compasión y el temor aspectos decisivos de la asimilación trágica, no está desligado del enfoque entusiástico generado principalmente por la música dentro de este tipo de representaciones. Aristóteles no niega esta particularidad, y a pesar de que efectivamente no le dedique una especial atención comprendiéndola como un mero aditamento, sí indica cómo su presencia es decisiva dentro de los cambios purgativos ejercidos en otros padecimientos:

... la música afecta la cualidad de nuestros caracteres, y que la afecta lo muestran, entre otras muchas cosas, las melodías de Olimpo; todos, están de acuerdo en que estas melodías producen entusiasmo en las almas, y el entusiasmo es una afección del carácter del alma. [...] y es en los ritmos y las melodías donde encontramos las imitaciones más perfectas de la verdadera naturaleza de la ira y de la mansedumbre, de la fortaleza y de la templanza, así como de sus contrarios y de todas las demás disposiciones morales ${ }^{22}$ (la experiencia lo demuestra, ya que nuestro estado de ánimo cambia cuando los escuchamos). La aflicción y el gozo que experimentamos mediante imitaciones están muy próximos a la verdad de esos mismos sentimientos. [...] en las melodías mismas hay imitaciones de los estados morales ${ }^{23}$.

20. P. Laín Entralgo, La curación por la palabra en la antigüedad clásica, Madrid: Revista de Occidente, 1958, p. 269.

21. A pesar de lo expresado, Nietzsche asumiría siempre que de la catarsis se extrae un efecto calmante y, por ende, contradictor del acrecentamiento fisiológico. Es en este sentido como extrapola el efecto señalado hacia una consideración de tipo moral que tiende a presentar una imagen más ficticia que real frente a los alcances de la exégesis aristotélica.

22. Ethikón: morales en el sentido de disposiciones del carácter.

23. Mimémata ton ethón: imitaciones de los caracteres (Aristóteles, Política, VIII, 1339 b431340 a43; Madrid: IEP, 2005). 
Este fragmento señala cómo otras afecciones o padecimientos se incorporan imitativamente a través de los diversos efectos que genera la música. Esta aclaración brinda al lector la oportunidad de establecer la conexión entre la oscuridad de la definición de la tragedia en que se involucran la compasión y el temor con otro tipo de afecciones que allí no se hacen explícitas. Pero en la indicación que Aristóteles plantea se hacen evidentes las disposiciones morales semejantes a la compasión y el temor, y por las cuales es imprescindible el sentido catártico que el estagirita consigna como objetivo de la tragedia. De esta manera es viable asimilar que la catarsis a la que apunta no es un enfoque desestimable, pues a ella se dirigen aspectos centrales de la representación trágica cuyas características están permeadas por el dominio entusiástico allí revelado. Estos aspectos no estaban vedados al público antiguo y son reconocidos por Nietzsche mismo, por lo cual su postura frente a Aristóteles parece tener un fondo equívoco en el que no se reconoce explícitamente su validez, aunque en otras referencias se interprete de un modo distinto el sentido entusiástico y, por ende, catártico de la tragedia. Hay que recordar el hecho de que, a diferencia de Nietzsche, Aristóteles no está planteando una constitución trágica de la existencia griega, sino tan solo reuniendo dentro de su exposición un conjunto de atributos y experiencias que son imprescindibles en la tragedia y conllevan la incorporación de estados entusiásticos como generadores de una catarsis.

Una experiencia y tonalidad distinta es la que muestra Nietzsche cuando en «El drama musical griego» incorpora elementos catárticos derivados de la música aunque expresados a partir del entusiasmo extático de los servidores dionisíacos. Aquí Nietzsche presenta una problematicidad que no debemos dejar de lado, dado que su interpretación determina el entusiasmo como comunión metafísica y no como presencia de una expresión catártica del pueblo griego. A esta última especificidad correspondiente a la exposición aristotélica se enfrenta airadamente Nietzsche, aunque no de manera acertada. Es posible que no estén del todo esclarecidos los puntos en que se evidencia radicalmente la relación existente entre el éxtasis dionisiaco, el entusiasmo allí establecido y las experiencias catárticas debidas. Por supuesto, Nietzsche no determina en este caso ningún tipo de catarsis dentro de su asimilación del contenido dionisíaco, aunque en este sea estimable concebir una relación con ella que no puede desconocerse, puesto que en dicho éxtasis sí opera una descarga fundada principalmente en los efectos a que conduce la música. Música y catarsis están íntimamente ligadas, a ello apunta principalmente el texto aristotélico que acabamos de citar, y en el mismo sentido, aunque ligado al contenido metafísico, Nietzsche interpreta el estado en que «el efecto omnipotente de la primavera, que se manifiesta tan de súbito, incrementa aquí también las fuerzas vitales con tal desmesura que por todas partes aparecen estados extáticos, visiones y una creencia en una transformación mágica de sí mismo» ${ }^{24}$.

En este texto se encuentra el contenido dionisiaco a partir del proceso en que el individuo se transforma y experimenta un estado en el que se halla fuera de sí. Este tipo de catarsis proviene directamente de la concepción religiosa de exaltación dionisíaca que Nietzsche interpreta como estado extático orientado hacia la disolución de la individuación y comunión con la única realidad. Pero Nietzsche

24. F. Nietzsche, «El drama musical griego», en El nacimiento de la tragedia, cit., p. 202. 
no la reconoce, al menos directamente, como catarsis, mientras es casi obvio que el hombre presa de dicho estado la experimenta, pues es verdaderamente una descarga. De esta manera, Nietzsche tensiona la relación entre, por un lado, el sentido moral de la descarga ${ }^{25}$, el cual niega, y por otro, el aspecto vitalista que sí reconoce, dentro de los estados descritos anteriormente, a pesar de que ambos están presentes en la representación trágica que de manera tan clara ha descrito Aristóteles. Lo que debemos puntualizar aquí es que, justamente en este caso, la reciprocidad y contradicción de Apolo y Dioniso se ven demarcadas sin dificultad, por cuanto en la asimilación cabal de la experiencia trágica van paralelos el sentido moral ${ }^{26}$ y el extático.

Por supuesto, la catarsis tiene un contenido moral que es imposible rechazar por cuanto está allí involucrado el efecto psico-somático derivado de la mímesis trágica. En tanto Nietzsche está comprometido solo con la orientación extática de carácter metafísico, procura constituir una exégesis de la tragedia en la cual se expliciten los rasgos vitales de la misma. En concordancia con ello asume el veredicto aristotélico en relación al contenido purgativo como uno de los presupuestos más desacertados que se hayan determinado sobre el objetivo de la tragedia. El enfoque está altamente viciado por cuanto la desestimación de esta perspectiva implica el abandono de uno de los contenidos más importantes, en este caso, el efecto psico-somático derivado de la conjunción a que apunta la música con los efectos patéticos que generan la subsiguiente descarga. Por ello, la postura nietzscheana carece de validez si a ella se ligan las derivaciones que se encuentran realmente en el alma del espectador trágico, mucho más coherentes con las referencias dadas por Aristóteles. Pero es prudente señalar que el manifiesto del filósofo alemán procura identificar no simplemente los atributos de un fenómeno cultural como la tragedia, sino, ante todo, crear, como tirano del espíritu, un enfoque trágico en el que el contenido moral del apaciguamiento sea considerado nocivo, para identificar el aspecto positivo solo dentro del ámbito tonificador. Por supuesto, esta es la gran imposibilidad que Nietzsche registra para aceptar el veredicto aristotélico, incapaz de asumir la tragedia en concordancia con un efecto tranquilizador en el que la seguridad y serenidad propias del individuo, inmerso en los límites de sí mismo a través de la catarsis moral, puedan ser consideradas como un resultado de la manifestación trágica. Nietzsche, a pesar del hecho en la Grecia antigua, pretende ir más allá. Así se reconoce no al filólogo griego inquieto por una manifestación del espíritu sino al filósofo que ansía crear.

A pesar de que los comentarios sobre la catarsis son casi siempre negativos y circunscriben su apreciación a un talante del todo distinto frente al carácter tónico que Nietzsche identifica en la representación trágica, en La gaya ciencia expresa un concepto diferente en donde la apreciación con respecto a la recepción de la música y la poesía por parte del pueblo griego tiene una conexión estrecha con la posibilidad de encontrar en ella un estímulo, no tanto de vida como podría esperarse, sino de descarga purgativa de emociones. El comentario que realiza Nietzsche no solo da un punto de vista distinto en el que coincide con Aristóteles, sino que deja traslucir un carácter más acorde a la percepción griega del papel que ejercían la música y la poesía sobre los efectos trágicos, con lo cual el esbozo

25. El cual tendría en este caso una orientación apolínea, a la que no hace referencia Nietzsche.

26. Sentido al cual no es ajeno su relación fisiológica. 
psicológico en este caso adquiere una identidad dada desde otra dimensión de la cultura griega que Nietzsche reconoce, aunque la despliega en muy poco grado. Los comentarios hechos entonces en el parágrafo 84 del libro referido ofrecen la posibilidad de identificar una percepción muy distinta que es necesario tener en cuenta. «... mucho antes de que hubiera filósofos ya se le reconocía a la música la fuerza de descargar los afectos, purificar el alma, suavizar los ferocia animi...» ${ }^{27}$. Que la manifestación aristotélica se mueva dentro de estos mismos parámetros no hace falta recordarlo; de hecho, Nietzsche ilustra justamente los lineamientos desde donde el estagirita logra ubicar los efectos que la tragedia estimula en el espectador. De ahí que el núcleo del comentario citado posea una enorme importancia, pues contrasta enormemente con la tonalidad acostumbrada cuando Nietzsche describe los acentos trágicos en que, según su interpretación, se enmarca el pueblo griego. Y es que la descarga o catarsis derivada de la música no es una idea ajena a la mentalidad griega, y mucho menos a las posibilidades que la tragedia implica. Podemos inclusive circunscribir la naturaleza de la purgación trágica dentro del tríptico música, danza y poesía, indisoluble entre la idiosincrasia griega, dado que es bastante complejo poder dar cuenta de las tres desde ópticas contemporáneas, en las cuales son perfectamente distinguibles. Otra cosa ocurre, sin embargo, en la antigüedad griega. Allí las tres están completamente imbricadas, además de soportar un elemento purgativo y divino imposible de dejarse a un lado. La palabra mousikée ${ }^{28}$ no es ajena al elemento poético y literario. Así, «texto y música formaban un todo, eso es lo importante: no pasaba como en ciertos géneros modernos en que los connaisseurs atienden a la música y se desentienden de un texto mediocre. Pero era un conjunto en el que las dos partes colaboraban a la obtención de unos mismos efectos. Por eso leer una tragedia griega, por ejemplo, desentendiéndose del ritmo, la melodía, la danza, es leer algo incompleto» ${ }^{29}$.

La identificación del carácter purgativo de la música no es algo ajeno a la exégesis nietzscheana en torno al fenómeno dionisíaco. Los signos orgiásticos enmarcados en la misma se pueden considerar como elementos habituales que se reconocen tanto en Nietzsche como en la idea purgativa contemplada en Aristóteles. Cada vez que el filósofo alemán ataca los propósitos aristotélicos en relación a los efectos trágicos, omite ostensiblemente las relaciones que lo vinculan a aceptar el efecto catártico, a pesar de que no solo está conectado con su visión, sino que su presencia es algo difícilmente cuestionable dentro de la cultura helena.

\section{CONCLUSIÓN}

Las $r$ eferencias aristotélicas contenidas en los textos de Nietzsche muestran un panorama lleno de equivocidades que no necesariamente deben conceptuarse desde una óptica negativa. Ilustran una tensión en la que, si bien no son del todo coherentes las críticas al estagirita, confieren al ideario nietzscheano un punto de

27. F. Nietzsche, La gaya ciencia, OC III $\mathbb{\$} 84$.

28. El término mousiké (arte de las musas) no designa estrictamente lo que hoy entendemos como música, sino que está en concordancia con el ámbito poético-literario.

29. F. Rodríguez Adrados, «Música y literatura en la Grecia antigua»: Anuario de la Sociedad Española de Literatura General y Comparada (Madrid) III (1980), p. 136. 
referencia instaurado desde la contradicción y el paralelismo. Los enfoques en los que Nietzsche increpa las posiciones aristotélicas no confrontan de manera rigurosa las disposiciones y alcances de las mismas, pero sí dejan claro cómo la filosofía nietzscheana está interesada en poner en evidencia su demarcación a través de la perspectiva trágica, no como una descripción de efectos o posibilidades éticas y políticas, tal como acontece en el dominio aristotélico, sino como determinación fundamental del movimiento a que está abocada la metafísica nietzscheana. Por supuesto, solo con la confrontación y esclarecimiento de ambas posturas no es suficiente para estipular la validez de las mismas en relación al fenómeno sobre el cual ambas discurren: la tragedia griega. Sin embargo, de dicho acercamiento no puede eludirse el contenido y tonalidad hacia donde apunta el rasgo nietzscheano que enfoca su filosofía hacia la comprensión de la sabiduría trágica. En esta característica se inscribe tanto la animadversión como la contradicción efectiva del pensamiento aristotélico, en el cual, a pesar de que hemos precisado enfoques coincidentes que Nietzsche no reconoce, se registra igualmente una orientación absolutamente distinta en lo referente al enfoque fundamental demarcado por una filosofía no trágica que, por supuesto, en nada aminora el destino mismo de su esquematización. 